\title{
The Subject in Cognitive Psychotherapy
}

\author{
Isabel Caro-Gabalda
}

University of Valencia, Spain

\begin{abstract}
Título: El sujeto en Psicoterapia Cognitiva.
Resumen: En este trabajo se reflexiona sobre el tipo de sujetos implícitos en psicoterapia cognitiva. El modelo cognitivo de Beck, al que podemos considerar como un modelo racionalista y modernista, ejemplificará estos sujetos. En primer lugar, debemos situar a la terapia cognitiva en un contexto histórico y relacionarla con un sujeto caracterizado por poseer racionalidad y la habilidad para observar y detectar cogniciones, emociones y conductas. Este trabajo desarrolla todo ello introduciendo tres tipos principales de sujetos. El primero es el sujeto introspectivo y consciente, que es capaz de observar lo que pasa en su interior, tiene acceso libre y es consciente de su mundo cognitivo. El segundo, el indigente cognitivo, describe al tipo de sujeto que entra en psicoterapia cognitiva. El último sujeto identificado es el científico entrenado que es capaz de desarrollar un conocimiento más objetivo, cambiando esquemas disfuncionales y cogniciones distorsionadas. Este sujeto es el que se busca en psicoterapia cognitiva. Podemos relacionar estos sujetos con algunas de las características principales de la terapia cognitiva, como el concepto de $\mathrm{ABC}$, los procedimientos de evaluación, las técnicas cognitivas o la relevancia de los esquemas. Finalmente, el trabajo sugiere algunos elementos de estudio que pueden contribuir a la evolución teorética y clínica de la psicoterapia cognitiva.

Palabras clave: Sujeto en psicoterapia cognitiva; introspección; consciencia; indigente cognitivo; científico entrenado.
\end{abstract}

\section{Introduction}

This paper discusses an issue that is relevant to the field of Psychology and Psychotherapy. Within any psychological model it should be understood that there are different and implicit types of subjects. From the beginnings of psychoanalysis until the present psychological treatments or perspectives such as cognitive neuroscience, we should emphasize the impossibility of understanding psychological models without considering the subjects implicit both between and within them.

From an etymological perspective, the word subject comes from the Latin word subiectus, meaning, what is under. As defined by Danziger, the subject, in a philosophical context, is the source of actions and ideas, an active principle (Brock, 2006). Any action belongs to someone (Fierro, 1996; Pérez, 2004).

The main aim of this paper is to address the subject embedded in cognitive or rationalist therapies. The field of cognitive psychotherapy is today firmly established and we cannot neglect its contribution to the field of psychotherapy. However, there are great epistemological, philosophical or ontological differences between rationalist and constructionist models (Mahoney, 1991; Mahoney \& Gabriel, 1987; Neimeyer, 1993) or between modernist and postmodernist

* Dirección para correspondencia [Correspondence address]: University of Valencia. Faculty of Psychology. Department of Personality, Assessment and Psychological Treatments. Avda. Blasco Ibáñez, 21. 46010, Valencia (Spain). E-mail: Isabel.Caro@uv.es
Abstract: This paper discusses the various subjects embedded in cognitive psychotherapy. The cognitive model developed by Beck, considered as a rationalist and modernist model, will exemplify these subjects. Cognitive therapy should be placed in the modernist historical context and related to a subject characterized as having rationality and the ability to observe and detect cognitions, emotions and behaviors. The paper develops this background introducing three main subject types. The first is the introspective and conscious subject, who is able to observe what is within oneself, has free access, and is conscious of one's cognitive world. The second is the cognitive miser that describes the subject who enters into therapy. The final subject identified, is the trained scientist who is able to develop a more objective knowledge, changing faulty schemas and cognitive distortions. This subject is the one most looked for in cognitive therapy. We could connect these subjects to some of the main elements of cognitive therapy such as the concept of $\mathrm{ABC}$, assessment procedures, cognitive techniques or the relevance of schemas. Finally, the paper suggests some issues for study that could contribute to the theoretical and clinical evolution of cognitive psychotherapy.

Key words: Cognitive therapy subject; introspection; consciousness; cognitive miser; trained scientist. perspectives (Caro Gabalda, 1995). ${ }^{1}$ Due to these differences, this paper focuses, exclusively, on the rationalist or modernist model or what can be termed as a classical cognitive model, such as the cognitive restructuring perspective, exemplified in Beck's model. This model has evolved over time, but it maintains its own specific and distinctive issues.

Our main assumption is that cognitive/rationalist therapy has not developed an explicit account regarding the subject that this therapy addresses. However, there is a subject implicit in this model, a subject for the different cognitive actions. We assume that a theoretical examination of the implicit "subject" has implications in terms of a theoretical and clinical comprehension of the cognitive restructuring model.

Before explaining the subject under the cognitive model, we need to emphasize some of the main characteristics of cognitive psychotherapy, connected with specific actions cognitive therapists ask their patients. This will provide the required background for the development of the main issues of this paper.

\section{What is cognitive therapy?}

From the outset, cognitive therapists have offered the limits and range of their model (Beck, Rush, Shaw \& Emery, 1979; Clark, Beck \& Alford, 1999; Hollon \& Beck, 1994), showing a wide range of efficaciousness (Hofman, Asnaani, Vonk,

\footnotetext{
1 Although nobody wants to be considered as a rationalist (Mahoney, 1995), we assume that this distinction still makes sense, exemplifying the different cognitive perspectives. Clark, Beck \& Alford (1999, p. 62) recognized that "cognitive theory adopts a realist and modernist epistemology as opposed to an antirealist and postmodernist perspective".
} 
Sawyer \& Fang, 2012). From a brief general perspective, cognitive therapy focuses on our constructions and interpretations of reality: on how we attach meaning to events and on the influence of meaning on our mental well-being. From the moment that a patient enters into a cognitive therapy session, the therapist looks for specific activities or actions, playing a guiding role. Cognitive therapists are "teachers" and patients are "students" that learn about the influence of their worlds of meanings during therapy. In this sense, therapists guide patients toward the discovery of the influence of thought on their well-being, right until the outset of therapy (Caro Gabalda, 2011).

Let us take the ABC formulation (Ellis, 1958, 1984) as an example. The ABC model is a main focus of RationalEmotive-Behavior Therapy, but it is easy to translate and generalize it in relation to other cognitive restructuring models. "A" stands for activating events; "B" for the world of beliefs or, for the whole world of our constructions and interpretations; and, finally, " $C$ " stands for emotional and behavioral consequences. Patients receive, from their therapists, an explanation of their problems that helps them to understand the relevance of the interpretations and constructions of their experiences.

This is tied to the importance of cognitive formulation (Persons, 1989; 2008). The patient should look for and "validate" this cognitive formulation, so how patients interpret reality has a great relevance. The main therapeutic activity of patients is to provide a host of cognitions (also related to their emotions and behaviors) that sustain the cognitive formulation. The Daily Record of Dysfunctional Thoughts (Burns, 1980) is an excellent example of this first group of actions.

This cognitive activity is not only demanded at the beginning but during therapy. Patients should focus actively and extensively on their thinking, their cognitions, and on how they perceive and interpret situations until the conclusion of therapy. This cognitive process is just the beginning of another that is more difficult and personally demanding for patients. Patients should act on what has been identified. Patients should work extensively with their thinking processes and look for a cognitive change, related to becoming detached observers from their thoughts, looking for evidence for or against these thoughts to develop an alternative thinking and to modify schemas and core beliefs. This is usually done in the context of the Socratic dialogue. The therapist provides the appropriate climate for this cognitive work, emphasizing therapeutic alliance, guided discovery and collaborative empiricism.

These activities and actions belong to a cognitive subject. Guided by the above activities and cognitive actions, and by some of the main characteristics of cognitive therapy, what kind of subject is inferred? We will explain this issue focusing, first, on the implicit subject in the historical context of cognitive therapy.

\section{What kind of subject is embedded in cognitive therapy?: A historical perspective}

As a scientific discipline, psychology was part of a modernist tradition (Gergen, 1991, 1992; 2001; Kvale, 1992). We could consider psychotherapy as a project of modernity. The main modernist trends explain, as a kind of therapy, the classical, rationalist cognitive psychotherapies (see, also, Woolfolk \& Richardson, 1984). Cognitive psychotherapies exemplify all the basic elements of "modern times" (Ibáñez, 1993).

Following Gergen (1992, p. 19) we have to assume that the psychological sciences participated in the modernist romance. Four issues are relevant in this context: (a) belief in a knowable world, defending a basic subject matter, (b) belief in universal properties that can be discovered in relation to this subject matter; (c) belief through method; and finally, (d) belief in the progressive nature of research. Translating this to the cognitive therapy field we could assume that cognition, in a wide sense, exemplifies the basic subject matter. The influence of our cognitive world and on how faulty and distorted thinking can be modified, via cognitive procedures, is central. Based on this subject matter, cognitive therapy aims to develop clinical and useful procedures.

According to Gergen (2001), the modernist tradition makes us defend the fact that mental processes are available for objective study, and are causally related to environmental inputs and to behavioral consequences. The modernist assumptions that Gergen emphasized have striking similarities with the cognitive therapy ABC model (see above).

Cognitive therapy assumes the rational justification of a logical empiricist philosophy. The nature of the subject matter and the causal networks in which it is embedded need to be examined, but results from this method are impersonal. From research, we obtain value-neutral truths. We should develop reliable, valid methods that are "objective", uncontaminated by human wishes, fears, evaluations, values, etc. (Christopher, Richardson \& Christopher, 2003). The reliance on demonstrating the effectiveness of the cognitive model (Lyddon \& Jones, 2001) exemplifies this. Results could be objective and valid when the method used has followed reliable and proper guidelines.

\section{The Cartesian, modernist subject}

As Rosenau (1992) stated the subject is a symbol of modernity. We could relate this modernist scientific context to a particular perspective on human subjects. A perspective which cognitive therapy inherited as part of its modernist background, and which is shown in its therapeutic conceptualization and formulation of clinical cases and therapeutic procedures.

Classical cognitive therapies are structured around a Cartesian subject. We could consider human beings, therefore, as atomistically discrete centres of experience and action (Christopher et al., 2003). This subject is a unified, mono- 
lithic, reified, essentialized, capable of being fully conscious, and able to develop a fully rational action (Lather, 1992).

This type of discussion regarding the human subject derives from the thinking of Descartes. In the Second Meditation Descartes asked:

What am I then? A thing which thinks. What is that? A thing which doubts, understands, affirms, denies, wills, is unwilling, and also imagines and feels (Cottingham, 1978, p. 208)

Based on Foucault (1975) we could translate the modern self and its relationships to the social scientist that develops techniques to observe, measure, predict and control a subject's behavior, to the cognitive therapy field. The most relevant characteristic of this modernist self is selfconsciousness (Caro Gabalda, 2003). The Cartesian view implies distancing and reflexivity. In this last sense, the "cogito" is the basis for all knowledge (Pérez, 2012).

This conceptualization makes us certain of the existence of my mind (Seoane, 2005). The subject has authority over consciousness materials, "an authority which has its basis in the concepts of reason, logic and truth" (Lather, 1992, p. 121). Reason and observation are key elements of the modernist, rationalist subject (Gergen, 1991). ${ }^{2}$ Self-reflection makes us feel secure, but, then, the self is separated from the material world and from history, and becomes an isolated individual that must conquer unknown territories (Seoane, 2005).

Cognitive therapy exemplifies the modernist, rationalist subject, defending a human being that becomes both, object and subject. Object because the subject matter, as we have previously stated, is the whole patient's cognitive world, and subject because the patient is the direct agent of the cognitive change (Caro Gabalda, 2003).

The subject behind these cognitive models will be a central homunculus that construes reality, reacting to an external reality. The homunculus could be considered an unproductive and paradoxical idea (Minsky, 1985) and there is a lack of agreement about it, for instance, in the field of cognitive sciences (Baddeley, 1998; Monsell \& Driver, 2000; Parkin, 1998). However, some kind of central agent could be seen embedded in this perspective. Humans are rational beings, whose behavior is a consequence of how they pay attention, observe the world, and adapt to it (Gergen, 1991). This central homunculus is relevant for the understanding of the perspective of cognitive psychotherapy. There are abstract characteristics of the human being, referred to as schemas, cognitive distortions, faulty information processing, that a central agent coordinates and modifies. This central agent needs to discover the patient's inner world, make sense of it and reconstruct it.

\footnotetext{
2 A note of caution should be considered here as this is not the only way to consider human rationality. We have followed a psychological and therapeutic perspective on human rationality, based on our understanding of a cognitive restructuring perspective, but this rational subject could have a different basis if we explore other fields. From an economical point of view, for instance, the human being is a "Homo oeconomicus". Following Shirrmacher (2014), human beings are rational when they look for their benefit being coherent with their own rules.
}

The therapist addresses this kind of individual just described. Although this subject is not explicitly recognized or elaborated on, we need for our therapeutic work an acting, rational subject. The cognitive subject uses rationality to understand and deal with his or her problems. Human beings are able to get a true understanding of themselves and their worlds. This understanding is the basis for rational belief and action (Martin \& Sugarman, 2000).

In cognitive models, the information obtained from our experiences has a hierarchical structure. Our experiences are passive, subjected to codification, storage, retrieval and modification due to previous knowledge structures. This requires, according to Osatuke et al. (2005) a central agent in charge of retrieving and applying relevant information. This corresponds to what Fay (1987, cited in Lather, 1992, p. 102) calls a "metaphysics of human agency", that is, "an inflated conception of the powers of human reason and will".

For development of this modernist, rationalist subject, we need to answer the following question: as therapists what do we expect from the patient treated under a rationalist model? To answer this, we need to consider three types of subjects under this cognitive therapy model. These three subjects develop, we could assume, the rationalist or modernist subject just described. The first is the introspective and conscious subject able to get free "access" to his or her cognitive world. The second is the subject as a cognitive miser, in a critical sense, which explains what the patient does and, consequently, his/her psychopathology. Finally, we will focus on the subject as a trained scientist; the subject looked for or addressed in cognitive therapy.

\section{The introspective and conscious subject}

We could understand patients' problems through different cognitive structures and processes behind their affective, motivational, behavioral and cognitive symptoms. The individual is similar to or identified with the functioning of the mind. The patient in front of the therapist is identified with what he/she is thinking. In cognitive therapy, we deal with a thinking subject. For this reason, the subject should be able to get a free and privileged access to his or her thinking processes.

The history of Psychology has focused extensively on introspection. A detailed review is not appropriate here, but there are classical (Danziger, 1980; Pinillos, 1983) or more recent descriptions (Costall, 2006) regarding the role and history of introspection in Psychology. William James (1890) defined introspection as "looking into our own minds and reporting what we there discover" (p. 185). What we discover, then, are states of consciousness. Unfortunately, as we do not have a psychocospe (Pinillos, 1983), we need to have "something" that allows us to get access to our cognitive therapy materials. If we talk about introspection we have to remember what James (1884) said when he advised us about the differences "between the immediate feltness of a mental state and its perception by a subsequent act of reflection" (p.1). 
A more recent consideration emphasizes that introspection "involves an attending to the content of one's consciousness and nothing more than that" (Overgaard, 2006, p. 631).

Consciousness, therefore, is also relevant to the field of cognitive therapy. According to Frith and Rees (2007) cognitive therapy uses the term "cognitive" for referring to knowledge, beliefs and attitudes which are key components of consciousness. As Tye (2007) assumed, our mental states cannot fail to be conscious. Even if one does not know how the process has been produced, there is a consciousness, therefore, of different things such as the noises on the street and the sweet memories of the past. Consciousness, as well as introspection, is a complex phenomenon both for philosophy and for psychology (Robinson, 2010), and difficult to define (Frith \& Rees, 2007). As Pinillos (1983) said: "consciousness is eluding, it avoids definition, and, obviously, is not a public matter; two centuries of philosophical inquiries and one century of scientific psychology has not unveiled its face" (p. 12).

According to Lambie and Marcel (2002), psychologists use consciousness, first as awareness, a kind of knowing (by acquaintance), a second order awareness or reflexive consciousness. Secondly, consciousness refers to phenomenology (what it's likee) or first order phenomenal experience.

A classical paper from Radford (1974) distinguished between the ranges of activities of subjects that could be considered as introspection. Subjects could self-observe their mental events, reporting their experiences. Secondly, subjects could recount their experiences, that is, self-report, but without trying to be objective. Cognitive therapy acknowledges both of them. For example, Beck (1976) said:"... he can use, with the proper instruction, to deal with these disturbing elements in his consciousness... Man has the key to understanding and solving his psychological disturbance within the scope of his own awareness" (p. 3) (italics in original); or later on "...since cognitive phenomena are readily observable by the patient through introspection" (p. 4). Introspection is so important that "cognitive techniques are most appropriate for people who have the capacity for introspection and for reflecting about their own thoughts and fantasies" (Beck, 1976, p. 216).

In cognitive therapy, patients are encouraged to focus on many different things: the situation they are experiencing, how it is constructed, and the kind of emotions and behaviors involved. Patients self-observe themselves and inform others by written and verbal communication. Therapists use self-reporting measures for identifying automatic thoughts, their underlying schemas and the corresponding cognitive distortions (Yurica \& DiTomasso, 2005).

There is a third activity according to Radford (1974): thinking aloud, that could be found in cognitive therapy, or therapy in general, if we consider those instances where patients are focused on a particular situation and encouraged to think aloud about what they feel, experience or think regarding a particular situation (Dunkley, Blankstein \& Segal,
2010). Although we cannot directly compare cognitive therapy work to the classical and present experimental and research traditions that focus on introspection and consciousness (see, for instance, issues of journals such as Consciousness and Cognition and the Journal of Consciousness Studies) we believe that two of the most relevant activities of the cognitive therapy subject are introspection and consciousness.

Introspection and consciousness form the basis of the assessment of the cognitive world. This is evident when patients are in the process of a clinical interview, or simply answering a therapist's question such as "What goes through your mind when you are feeling sad?" To ask patients about what goes through their minds is one of the simplest methods to detect automatic thoughts. This introspective questioning is encouraged during or outside of a session, but the cognitive process depends on the patients' ability to have a conscious access to the cognitive material (Yurica \& DiTomasso, 2005). Furthermore, when patients are answering a rating scale, this reflects a minimal and abbreviated act of introspection (Rosenbaum \& Valsiner, 2011).

Cognitive assessment depends, mainly, on self-reports. Patients report their thinking and their problems in a structured, unstructured, concurrent or retrospective way (Dunkley, Blankstein \& Segal, 2010). Books on cognitive assessment skip the issue of introspection and consciousness. The question, often asked, "can patients have a "true" access to their minds?" is not addressed in the cognitive therapy field, although cognitive assessment tasks of any kind rely on this access. The classical paper from Nisbett and Wilson (1977) is an example of the difficulties subjects have getting access to how their minds work. However, reflecting on this issue from an epistemological perspective, Goldman (2004) assumed that "introspection is accepted as an evidential source by most epistemologists. In making this acceptance, epistemologists go along with people's general disposition to form beliefs about their current mental states (sensations, propositional attitudes, emotions) based on their 'awareness' of these occurrences. Self-awareness or introspection is the source that confers a prima facie- warrant on these beliefs" (p. 4).

Of additional interest is the treatment that cognitive therapists give to introspection in terms of data and method (Radford, 1974). Cognitive therapy assumes a Cartesian point of view that considers introspection as direct and incorrigible (Costall, 2006) so that the individual knows his or her mind better than anyone else does (Gillespie, 2006). The Cartesian rationalist subject, again, appears to explain some of the main premises of cognitive therapy.

The consequence of introspection as data and as method reflects a belief in the "accuracy" of the patients' inner view of their cognitive world. Both, patients and therapists took at face value the results of introspection and of consciousness. Answers to questionnaires (for instance, the BDI) or the filling out of homework assignments such as the Daily Record of Dysfunctional Thoughts reflect what is going on. Even emotional experiences (at least, before therapy) have phe- 
nomenological "truth" for cognitive therapy (Lambie \& Marcel, 2002).

Through introspection, patients will offer a 'testimony' (Goldman, 2004, p. 6) of their cognitive and emotional world. For cognitive therapy, we could have access and measure cognition. Although it is not assumed that all cognitive activity is fully conscious, deliberate, effortful or a controlled processing (Clark, 1995). We should recognize that cognitive therapists are not so naive as to think that introspective data and procedures, and conscious access, reflect all that is "within" patients' minds or that patients could be conscious of all the cognitive processes. However, the treatment that therapists give to introspective activities and their consequences make us consider and revalidate the conceptualization noted above under the Cartesian view. Patients' self-reports are a 'testimony' (Goldman, 2004) of something "true". Unfortunately, there is no reflection on the issue that when subjects attend to something, this affects and creates experiential content (Marcel, 2003). We could assume that patients' accounts are incomplete, and that the therapist's task is to help the patient "to peel the onion". In this sense, we cannot forget, as James poetically said, that, "our mental life, is like a bird's life, and seems to be made up of an alternation of flights and perchings" (James, 1884, p.2).

Let us assume that cognitive assessment relates more to retrospection than with observation, which is closer to the Jamesian perspective on introspection (James, 1890). We are not making the point that cognitive work reflects an introspective kind of psychology; only that, in therapy, we should take into account introspection and consciousness. They are useful tools for therapists.

To conclude, the cognitive therapy model acknowledges but does not fully discuss the capacity of access, of introspection and consciousness. It is considered as something subjects possess, although individual differences should be recognized. It is assumed, also, that subjects are able to reflect on different issues, which are used to make sense about what is happening. The content, the process and the aim of cognitive therapies require a conscious and introspective human being. The following two perspectives on the cognitive subject depend on this.

\section{The cognitive miser subject: what is wrong within this subject?}

Early cognitive psychology approaches emphasized the rationality of human beings and their ability to function as scientists (Seoane, 1982). However, it was emphasized later on that this perspective did not give a proper account of human beings. The metaphor of human beings as scientists was discarded in favour of the cognitive miser.

The term cognitive miser comes from the field of social cognition (Fiske \& Taylor, 1984; Garzón, 1984). From this framework, Operario and Fiske (1999) describe subjects as not thinking rationally or carefully, taking instead cognitive shortcuts (e.g., heuristics, schemas, attributions, etc.). For this approach, subjects are well-adapted perceivers who sacrifice accuracy (i.e., a careful and planned thinking) for efficiency by using schemas, scripts, and any kind of simplifying perceptual strategies. These categories could be considered efficient ways of thinking. The subject does not think like a scientist, as described below, does not carefully analyse reality, and is unable to reach a weighted evaluation of the data. The individual is lazy, a mental sluggard and a cognitive miser (Bargh, 1999; Fiske \& Taylor, 1984; Rodríguez, 1993).

The reliance of Beck's model upon the schema concept (see, for instance, Clark et al., 1999) allows us to use the metaphor of the cognitive miser in the cognitive therapy field. Moss and DiCaccavo (2005) point out that the cognitive miser is one of the most influential models of the schema function. "The main premise here is that schemata are used as heuristics to reduce an individual's overall processing load. Schemata guide information processing to preferentially encode and assimilate schema consistent information" (Moss \& DiCaccavo, op. cit., p. 512).

Although under this perspective individuals are welladapted perceivers, cognitive therapy assumes a quite different perspective. For cognitive therapy, these shortcuts could be non-adaptive and dysfunctional. The subject will resemble, perhaps, more a cognitive monster (Bargh, 1999). The individual is unable to process all the information and needs to use several structures (such as core beliefs, schemas, etc.) to facilitate this task (efficiency and cognitive facilities) but this has emotional consequences. These shortcuts favour a cognitive vulnerability or a stress-diathesis model (see for instance, Dozois \& Beck, 2008) which is unavoidable and nonadaptive.

Within a therapeutic context, therapists have in front of them an individual with a limited processing capacity that uses unscientific, although effective strategies. From this framework, the individual is degraded in the hierarchy of knowledge (separated from genuine scientific knowledge). The individual is thrown out of the wisdom paradise. People do not function as scientists, but use tricks, strategies, heuristics, previous beliefs, etc. (Seoane, 1982), or dysfunctional schemas and distorted cognitive processes in the cognitive restructuring therapy field. We may assume this is an appropriate perspective to understand some characteristics of the cognitive therapy subject. We will now develop the above issues in relation to the role of schema in cognitive therapy.

\section{The schema in cognitive therapy}

Beck (1964; Beck et al., 1979) introduced his theory in relation to the concept of schema for explaining patterns of thinking in depression. For Beck (1964): "a schema is conceived of as a structure used for screening, coding and evaluating impinging stimuli (p.562)"”...; “... the schema abstracts and molds the raw data into thoughts or cognitions".

A schema is a stable pattern that enables us to give meaning to situations and decide what to do. Schemas could 
be functional and adaptive. As a cognitive miser subject, the patient could use schemas to interpret and predict information quickly. The subject, therefore, does not need to use a great amount of mental processing capacity to deal with the demands of a situation (James, Southam \& Blackburn, 2004).

However, problems arise if schemas are pervasive and hypervalent. According to the cognitive model, in psychopathological conditions, schemas tend to be hypervalent and dysfunctional. In depression, for instance, dysfunctional schemas become more and more active, and patients lose control over them. The cognitive organization of patients becomes fully autonomous and patients are unable to use more functional schemas (Beck, et al., 1979).

The efficient cognitive processor, therefore, is no longer efficacious and needs to work with his/her schemas in order to achieve a clinical change. However, as far as the therapeutic perspective on schemas is concerned, we should emphasize that the cognitive miser needs guidance and redirection. Anything that has become autonomous needs recognition and modification following specific cognitive therapeutic strategies. More time needs to be spent finding out what is behind our cognitive world, since shortcuts are no longer efficacious? This is related, obviously, to cognitive formulation, and especially to the use of cognitive techniques.

\section{Case formulation}

We could see the above ideas, in cognitive therapy case formulation, one of the main cognitive therapeutic strategies (Persons, 1989, 2008). The case formulation implies the understanding, conceptualization and formulation of patients' problems related to the reliance on self-schemas, maladaptive beliefs and assumptions, negative automatic thoughts, dysfunctional thinking, etc., that should, therefore, be detected. This formulation facilitates planning the appropriate intervention. The cognitive miser subject is using automatic cognitive strategies but in a dysfunctional, non-adaptive way.

As early as 1964, Beck said, "The affective response is determined by the way an individual structures his experience" (p. 567, italics in original), and that depends on the elicited schema. In this sense, the psychological substrate of depression is related to the cognitive triad, the role of schemas, and finally to the role of the faulty information processing based on cognitive errors (Beck, et al., 1979). Psychopathology is related to dysfunctional beliefs, meanings and memories and with specific biases that influence how we process information (Beck \& Dozois, 2011).

Therapy participants should acknowledge those structures and processes as well as the distorted cognitive content in an atmosphere of collaborative empiricism (Beck, et al., 1979) that requires the active participation and collaboration, of both patients and therapists. Although the atmosphere is one of collaboration and therapeutic alliance, the role of the therapist is similar to the role of a teacher, while the patients' role is similar to a student. Patients attend therapy to "learn" what is going wrong, to detect and, later, modify it.

\section{Cognitive techniques}

Cognitive techniques also reflect the relevance for cognitive psychotherapy of detecting those cognitive shortcuts that represent the faulty patient's cognitive world. "Cognitive techniques consist of: .... a microscopic or cross-sectional approach, focused on recognizing and evaluating specific cognitions; and the identification and modification of the misconceptions, superstitions, and syllogisms that lead to maladaptive reactions" (Beck \& Alford, 2009, pp. 307-308).

Cognitive handbooks describe different cognitive techniques (Beck, et al., 1979; Caro Gabalda, 2011). A relevant aspect shown in most of them is how the main aim of the various techniques is the modification of faulty thinking, and in addition, the discovery of dysfunctional thinking processes and patterns.

For instance, the detection of automatic thoughts looks for how these thoughts reflect dysfunctional cognitions. These automatic thoughts and images should be corrected by examining them empirically and testing, in real life, their validity. The search for alternative solutions aims to identify rigid patterns and topics in patients' thinking. The Daily Record of Dysfunctional Thoughts is a good reminder of patients' thinking mistakes and of how these maintain psychopathology. The detection of cognitive errors is a key issue in cognitive treatment. Through techniques such as the downward arrow or other techniques, we could identify schemas and core beliefs.

At this point, another metaphor comes into the arena: the subject as a trained scientist. We would like to assume that we have to differentiate between the individual that enters therapy, i.e., the cognitive miser that knows, constructs and understands, and the individual that wants to improve his or her knowledge and understanding. This subject is welcomed and looked for in therapy.

\section{Obtaining the therapeutic aims: the subject as a trained scientist}

Although Beck has insisted, from the very beginning, that his work is based on an information processing approach (Clark, et al., 1999), this adscription seems to be more nominal than sound (Brewin, 1989; Caro Gabalda, 2013; Dowd, 2002; Ibáñez, 1990).

The information processing approach relied extensively on the computer metaphor. For de Vega (1982) the human mind and the computer are processing systems, functionally equivalent. Based on Turings' universal machine this analogy is functional instead of physical. What is relevant is the software not the hardware. The computer should be able not only to simulate what a human being "does", but it should be able to simulate what a human being "is able to do" (Delclaux, 1982).

The metaphor of a naive scientist is characteristic of this field and assumes that the individual codifies, stores, trans- 
forms and retrieves information (abstract symbol lists without content). Here we are referring to the study of processes and structures, neutral, cold, empty of content and free of motivational and affective information elements (Seoane, 1982).

From this perspective, people's perceptions and daily interactions relate to testing lay hypotheses about the social world. Lay perceivers, therefore, proceed in a careful and planned manner when they try to discover their own and other's behavioral causes. Based on inferential, quasiscientific processes, people judge, develop intentions, and make behaviors (Operario \& Fiske, 1999). This perspective could be problematic. The human subject becomes a machine that operates and acts upon an imput, in order to produce an output. In this context, the subject is an active one, but not a subject of knowledge (Seoane, 1985). The information processing conception is seen as empty of content and affect (Seoane, 1982), which could be problematic for a therapy, such as the cognitive model.

Nevertheless, according to Gergen (1991), diverse cognitive therapies apply the computer metaphor. We partly agree with Gergen. If we assume the existence of thinking structures, human beings could be similar to sophisticated machines. However, if patients are cognitive misers that need guidance towards a better understanding, we should consider them as defective machines that need to be carefully repaired. However, as we mentioned above, if we take into account the cognitive therapy work we could assume that the subject should function as a scientist (see Kelly, 1955). We should establish a difference between three main issues: 1) the conceptualization and formulation of patient's problems, 2) how patients enter therapy as cognitive misers, and, 3) how patients should "dress" during treatment. As in the classical Saint-Exupery's tale, The Little Prince (1943), the metaphor of the scientist is related to the kind of dress the patient should wear in therapy: the patient should "dress" as a respectful and clever scientist that follows and answers the therapist's challenge for developing a more valid and improved knowledge.

The scientist metaphor is useful only to understand the aims of cognitive techniques. Briefly, the therapist aims to help patients detect what is wrong, following a certain logical order by analysing, looking at the advantages and disadvantages, considering alternatives, and checking all this in real life. This will produce an adequate output, that is, an alternative valid thinking that reflects reality. Distorted thoughts are similar to hypotheses that should be empirically verified. If there is evidence, the idea is supported, if not it should be rejected. Instead of a naive scientist, the cognitive patient becomes a trained scientist.

The therapist educates patients to become scientists and in doing so several issues have to be emphasized. First, that therapists use a particular style, the Socratic dialogue. Secondly, patients learn, through the different techniques, how to modify their distorted thinking, validating alternative conclusions. Finally, patients become rational subjects.

\section{Socratic dialogue: The context for becoming a sci- entist}

There is some controversy about what is implicit under the heading of the Socratic dialogue or Socratic questioning (Carey \& Mullan, 2004).

As Freeman (2005) explained, the Socratic dialogue is not a discussion or a debate. "The dialogue components of Socratic dialogue use a questioning format to facilitate the patient's movement toward greater recognition of areas, issues, and situations that cause difficulty" (Freeman, op. cit., p. 380). Through a process of guided discovery, patients are able to find and challenge their faulty conclusions (DeRubeis, Webb, Tang \& Beck, 2010). This challenge relies, very often, on the quest for evidence.

According to Beck and Alford (2009), the Socratic dialogue facilitates the therapist in providing the patient with a context to internalize the cognitive perspective. This is possible in a context of collaboration, in a supportive-direct manner, which helps patients to look for the evidence or lack of evidence for their beliefs and thoughts. The patients functioning as scientists learn, first, how to identify and question their beliefs and thoughts, in the context of the therapeutic sessions and the Socratic dialogue. The aim is to provide patients with a framework to work on their own thinking. Cognitive therapy work does not end with the therapy sessions but the patient applies it repeatedly, whenever he/she needs to. Patients, as trained scientific subjects, learn how to observe, detect, question and modify their thinking. They put into practice the ideal of the modernist self, explained above. The rationale of cognitive techniques and the Socratic dialogue, exemplify, also, some of the main actions of the subject undergoing cognitive therapy.

\section{Cognitive therapy techniques}

In one of the first books discussing his approach, Beck (1976) introduced some epistemological principles that clearly reminds us of some of the activities of the scientific subject. For Beck (op. cit., pp. 233-234) in order to correct their distortions, patients need to learn, (a) that the perception of reality is not reality itself ${ }^{3}$; (b) that their interpretations are based on fallible cognitive processes; and, finally, (c) that they should be able to test hypotheses, validating them through getting information and data.

These issues are particularly relevant in the context of cognitive therapy techniques. As a scientist, the cognitive therapy subject looks for evidence. We are not implying that cognitive therapy is exclusively based on reality-testing, but that looking for evidence is one of the best ways to modify distorted thinking and, in this sense, it is used extensively in

3 This reminds us of one of the core issues of the theory of General Semantics developed by A. Korzybski and considered as an antecedent of cognitive psychotherapies (Caro Gabalda, 1996, 2001, 2014; Mahoney, 1991; Meichenbaum, 1977). The general semantics assumption is that "the map is not the territory", or "we cannot identify words with facts" (Korzybski, 1933). 
cognitive therapy techniques. All of the most relevant cognitive techniques employ this reality testing. For instance, to modify automatic thoughts or basic schemas and beliefs, patients should weigh up the advantages and disadvantages of maintaining them, examining and looking for the evidence for and against each thought, belief or schema (Beck et al., 1979; Blackburn, Davidson \& Kendell, 1990).

Cognitive therapy uses also, behavioral techniques to alleviate symptoms directly, or to aid cognitive change. Beck et al. (1979) emphasized that "... behavioral methods can be regarded as a series of small experiments designed to test the validity of the patient's hypotheses or ideas about himself" (p. 118) ....'behavior change is important insofar as it provides an opportunity for the patient to evaluate empirically his ideas of inadequacy and incompetence" (p. 119).

Although the scientific context is different from the clinical session the use of experiments closely reminds us of the role of experiments in a scientific milieu (Bennett-Levy, et al., 2004). For Padesky (2004) behavioral experiments are the crossroads of cognitive therapy, exemplifying the empirical nature of cognitive therapy.

\section{A scientist and rational subject}

The trained scientist that tests and validates beliefs based on empirical evidence, is a good example. This subject causes us to return to this rationalist perspective in cognitive therapy that develops from the modernist subject. From an epistemological framework (see Mahoney, 1991, Table 9.3, pp. 241-244) rationalism implies that knowledge is authorized as valid by logic or reason, and that reality is revealed via the senses. Patients should validate their knowledge. This is possible when patients make accurate copies that correspond to the "real world" (nature of representation) using "higher" intellectual processes that can and should direct feelings and emotions.

Although rationality is a matter of degree, and thinking could improve in many ways outside the therapist's office, cognitive therapy implies teaching patients how to think more rationally by looking for evidence of choices, hypotheses or personal goals regarding their problems (Baron, Baron, Barber \& Nolen-Hoeksema, 1990).

This rational framework does not only imply a subject who looks for evidence, validating knowledge, but a primacy, i.e., one of the consequences of this rationalist perspective is the reliance on "thinking" over "feeling". For Beck (1976), there is an essential relationship between the content of the interpretation of an event and a specific emotional response.

The primacy of reason over emotion has been a matter of controversy in the cognitive therapy field in particular (Mahoney, 1980; Safran \& Segal, 1990; also see Beck, 1996), and in psychotherapy in general (Ávila Espada, 2003; Greenberg, 2012). A great deal of the standard and classical cognitive therapy work relies and focuses on thinking processes, on "higher" intellectual processes as the way to get meaningful clinical changes (Mahoney, 1991). The rationalist subject observes, detects faulty thinking processes and applies different formulae to get a more valid thinking and control of one's emotions.

This is the particular challenge of cognitive therapy with respect to the subject in treatment: a challenge that entails the movement from the distorted to the rational. In this quest, the subject needs to be conscious and introspective about one's cognitive world, acknowledging cognitive shortcuts, developing a more valid knowledge and controlling emotions.

\section{Conclusion: implications for cognitive psycho- therapy}

We have tried to show the coherence between some of the main elements of cognitive therapy (exemplified through Beck's model) and three implicit subjects. However, it has to be pointed out that these three cognitive subjects are not the only possibility in the field of psychotherapy and cognitive therapy. Recent reflections, from different perspectives, point to different and alternative subject conceptualizations.

Basically, some of these perspectives centre on the narrative tendency in Psychology, but there are great differences between them. This is important, because part of cognitive therapy has evolved toward narrativity, defending another kind of subject (Bruner, 1986, 2002; Fisher, 1984) and the possibility of practicing cognitive therapy under the constructive narrative metaphor (Meichenbaum, 1995). However, other perspectives assume (Rosfort \& Stanghellini, 2009) that narratives are not cognitive stories to understand ourselves, which is implicit under cognitive therapy narrative perspectives (Gonçalves, 1994). Instead, based on Ricoeur, for instance, a dialectical perspective is defended where narratives articulate what the subject knows, and that the self is also a person among other persons (Rosfort \& Stanghellini, 2009, p. 286). To go into detail regarding these different narrative subjects would require a separate paper.

To conclude, this paper has described three main subject types, all of them relevant to cognitive therapy work. The first is the introspective and conscious subject that reflects basic actions for the development of the main activities of cognitive therapy. The widely used metaphor of human beings as scientists only partly represents the cognitive subject. We need to distinguish, secondly, either between the person that enters therapy, a cognitive miser, or at worst, a cognitive monster (Bargh, 1999), from the person that leaves therapy as a trained scientist. The rationalist, modernist subject embeds these three subjects.

Why should we study the cognitive subject? It will help, we assume, to achieve a better understanding of cognitive formulation, and cognitive work, from the perspective of the therapist and the patient. We suggest that this is important, because of the relevance of, and the difficulties for introspection and consciousness. Cognitive therapists are more 
concerned with showing the effectiveness of their procedures and on assumed and inferred schemas or cognitive structures than on the actions of a cognitive subject. That is, on the actions of the subject that coordinates these structures. According to Lambie and Marcel (2002), this could be an inheritance of cognitivism and be problematic for a full understanding of the subject under treatment.

Our main tenet is that if we want to contribute with a valid therapeutic procedure and improve its effectiveness, both for explaining patients' problems and for dealing with them, we need a theoretical and clinical reflection regarding the actions required from the subject of cognitive therapy. We could investigate, for instance, how we could facilitate our patients' access to the content and also to the consequences of their thoughts ?; Is training necessary to obtain this access?; How could therapists enhance introspection in patients who have difficulties using this process?; How could

\section{References}

Ávila Espada, A. (2003). ¿Hacia dónde va la psicoterapia? Reflexiones sobre las tendencias de evolución y los retos profesionales de la psicoterapia [Where does psychotherapy go? Reflections on evolution and professional challenges of psychotherapy]. Revista de la Asociación Española de Neuropsiquiatría, 23, 67-84.

Baddeley, A. (1998). The central executive: A concept and some misconceptions. Journal of the International Neuropsychological Society, 4, 523-526.

Bargh, J. A. (1999). The cognitive monster: The case against the controllability of automatic stereotype effects. In S. Chaiken \& Y. Trope (Eds.), Dual-process theories in social psychology (pp. 361-382). New York, NY: Guilford.

Baron, J., Baron, J. H., Barber, J. P. \& Nolen-Hoeksema, S. (1990). Rational thinking as a goal of therapy. Journal of Cognitive Psychotherapy, 4, 293-302.

Beck, A.T. (1964). Thinking and depression. II. Theory and therapy. Arcbives of General Psychiatry, 10, 561-571. Doi:10.1001/archpsyc.1964.01720240015003

Beck, A. T. (1976). Cognitive therapy and the emotional disorders. New York, NY: International Universities Press.

Beck, A. T. (1996). Beyond belief: A theory of modes, personality, and psychopathology. In P. M. Salkovskis (Ed.), Frontiers of cognitive therapy (pp. 1-25). New York, NY: Guilford.

Beck, A. T. \& Alford, B. A. (2009). Depression. Causes and treatment. Philadelphia, PA: University of Pennsylvania Press.

Beck, A. T. \& Dozois, D. J. A. (2011). Cognitive therapy: Current status and future directions. Annual Review of Medicine, 62, 397-409. Doi: 10.1146/annurev-med-05229-100032

Beck, A. T., Rush, A. J., Shaw, B. F., \& Emery, G. (1979). Cognitive therapy of depression. New York, NY: Guilford.

Bennett-Levy, J., Westbrook, D., Fennell, M., Cooper, M., Rouf, K. \& Hackmann, A. (2004). Behavioral experiments: historical and conceptual underpinnings. In J. Bennet-Levy, G. Butler, M. Fennell, A. Hackman, M. Mueller \& D. Westbrook (Eds.), Oxford guide to behavioural experiments in cognitive therapy (pp. 1-20). Oxford, England: Oxford University Press.

Blackburn, I. M., Davidson, K. M. \& Kendell, R. E. (1990). Cognitive therapy for depression and anxiety. Oxford, England: Blackwell.

Brewin, C.R. (1989). Cognitive change processes in psychotherapy. Psychological Review, 96, 379-394. Doi: 10.1037/0033-295X.96.3.379

Brock, A. C. (2006). Rediscovering the history of psychology: Interview with Kurt Danziger. History of Psychology, 9, 1-16. Doi: 10.1037/10934510.9.1.1

Bruner, J. (1986). Actual minds, possible worlds. Cambridge: Harvard University Press. therapists help patients to detect what's wrong with their thinking and to weigh evidence for and against their distorted thinking?, At what point should therapists adapt to patients' introspective capacities?; Do these capacities influence success in therapy?; etc.

We assume that the theory of cognitive therapy cannot neglect the issues mentioned in this paper. We suggest that, provided cognitive therapy has shown its efficacy and contribution to the field of psychotherapy, studies of these elements (e.g., regarding the improvement of introspective capacities and assisting individuals to become better rational scientists) will influence, and improve, the theoretical and clinical development of cognitive therapy.

Acknowledgments.- The author wishes to thank Professor Elena Ibáñez for her suggestions in an earlier draft of this paper and the comments from two anonymous reviewers.

Bruner, J. (2002). Making stories: Law, literature, life. LLC: Farrar (Reprinted in "The narrative creation of the self", In L. Angus \& J. McLeod, eds., pp3-14, Thousand Oaks: Sage).

Burns, D. D. (1980). Feeling good: The new mood therapy. New York, NY: Avon. Carey, T. A. \& Mullan, R. J. (2004). What is socratic questioning? Psychotherapy. Theory, Research, Practice, Training, 41, 217-226. Doi: 10.1037//00333204.41.3.217

Caro Gabalda, I. (1995). Pasado, presente y futuro de las terapias cognitivas [Past, present and future of cognitive psychotherapies]. Boletin de Psicología, 46, 115-160.

Caro Gabalda, I. (1996). The linguistic therapy of evaluation: A perspective on language in psychotherapy. Journal of Cognitive Psychotherapy, 10, 83104.

Caro Gabalda, I. (2001). General semantics-cognitive therapyconstructivism: A relational approach. In I. Caro Gabalda \& C. Schuchardt-Read (Eds.), General semantics in psychotherapy (pp. 324-352). Brooklyn, NY: Institute of General Semantics.

Caro Gabalda, I. (2003). La evolución cultural de las psicoterapias cognitivas: El largo y sinuoso camino [The cultural evolution of cognitive psychotherapies: The long and winding road]. In I. Caro Gabalda (Ed.), Psicoterapias cognitivas. Evolución y comparaciones [Cognitive psychotherapies. Evolution and comparisons] (pp. 23-41). Barcelona, Spain: Paidós.

Caro Gabalda, I. (2011). Hacia una práctica eficaz de las psicoterapias cognitivas [Toward an effective practice of cognitive psychotherapies]. Bilbao, Spain: Desclée de Brouwer.

Caro Gabalda, I. (2013). Lo cognitivo en psicoterapias cognitivas: Una reflexión crítica [Cognitive issues in cognitive psychotherapies: A critical reflection]. Boletin de Psicologia, 107, 37-69.

Caro Gabalda, I. (2014). El uso del lenguaje en psicoterapia cognitiva. Conceptos y técnicas principales de la terapia lingüistica de evaluación [The use of language in cognitive psychotherapy. Main concepts and techniques of linguistic therapy of evaluation]. Bilbao: DDB.

Christopher, J. C., Richardson, F. C. \& Christopher, S. E. (2003). Philosophical hermeneutics: A metatheory to trascend dualism in western psychology. History \& Theory of Psychology Eprint Archive (HTP prints). Retrieved from http: //htpprints.yorku.ca/.

Clark, D. A. (1995). Perceived limitations of standard cognitive therapy: A consideration of efforts to revise Beck's theory and therapy. Journal of Cognitive Psychotherapy, 9, 153-172.

Clark, D. A., Beck, A. T., \& Alford, B. A. (1999). Cognitive theory and therapy of depression. New York, NY: Wiley.

Costall, A. (2006). 'Introspectionism' and the mythical origins of scientific psychology. Consciousness and Cognition, 15, 634-654. Doi: 10.1016/j.concog.2006.09.008 
Cotthingham, J. (1978). Descartes on 'Thought'. The Philosophical Quarterly, 28, 208-214.

Danziger, K. (1980). The history of introspection reconsidered. Journal of the History of the Behavioral Sciences, 16, 241-262. Doi: 10.1002/15206696(198007)16:3<241::AID-JHBS2300160306>3.0.CO;2-O

Delclaux, I. (1982). Introducción al procesamiento de la información en psicología [ntroduction to the information processing paradigm in psychology]. In I. Delclaux \& J. Seoane (Eds.), Psicología cognitiva y procesamiento de la información [Cognitive psychology and information processing] (pp. 21-38). Madrid, Spain: Pirámide.

DeRubeis, R. J., Webb, C.A., Tang, T. Z., \& Beck, A. T. (2010). Cognitive therapy. In K.S. Dobson (Ed.), Handbook of cognitive-behavioral therapies (pp. 277-316). New York, NY: Guilford.

Dowd, E. T. (2002). History and recent developments in cognitive psychotherapy. In R.L. Leahy \& E.T. Dowd (Eds.), Clinical advances in cognitive psychotherapy (pp.15-28). New York, NY: Springer.

Dozois, D. J. A. \& Beck, A. T. (2008). Cognitive schemas, beliefs and assumptions. In K. S. Dobson \& D. J. A. Dozois (Eds.), Risk factors in depression (pp.121-143). Oxford, England: Elsevier.

Dunkley, D. M., Blankstein, K. R. \& Segal, Z. V. (2010). Cognitive assessment: Issues and methods. In K.S. Dobson (Ed.), Handbook of cognitivebehavioral therapies (pp. 133-171). New York, NY: Guilford.

Ellis, A. (1958). Rational psychotherapy. The Journal of General Psychology, 59, 35-49. Doi:10.1080/00221309.1958.9710170

Ellis, A. (1984). Expanding the ABCs of RET. In M. Mahoney \& A. Freeman (Eds.), Cognition and Psychoterapy (pp. 313-325). New York, NY: Plenum Press.

Fierro, A. (1996). Para una ciencia del sujeto. [For a science of the subject]. Barcelona, Spain: Anthropos

Fisher, W. (1984). Narration as a human communication paradigm: The case of public moral argument. Communication Monographs, 51, 1-22. Doi: $10.1080 / 03637758409390180$

Fiske, S. T. \& Taylor, S. E. (1984). Social cognition (1 ${ }^{\text {st }}$ ed.). Reading, MA: Addison-Wesley.

Foucault, M. (1975). Surveiller et punir [Discipline and punish]. Paris, France: Gallimard.

Freeman, A. (2005). Socratic dialogue. In A. Freeman, S.H. Felgoise, A. M. Nezu, C. M. Nezu \& M. A. Reinecke (Eds.), Encyclopedia of cognitive behavior therapy (pp. 380-384). New York, NY: Springer.

Frith, C. \& Rees, G. (2007). A brief history of the scientific approach to the study of consciousness. In M. Verlmans \& S. Schneider (Eds.), The Blackewell companion to consciousness (pp. 9-22). Oxford, England: Blackwell Publishing.

Garzón, A. (1984). La psicología social cognitiva [Social cognitive psychology]. Boletín de Psicología, 3, 67-88.

Gergen, K. G. (1991). The saturated self. New York, NY: Basic Books.

Gergen, K. G. (1992). Toward a postmodern psychology. In S. Kvale (Ed.), Psychology and postmodernism (pp. 17-31). London, England: Sage.

Gergen, K. G. (2001). Psychological science in a postmodern context. American Psychologist, 56, 803-813. Doi: 10.1037//003-066X.56.10.803

Gillespie, A. (2006). Descartes' demon. A dialogical analysis of Meditations on First Philosophy. Theory \& Psychology, 16, 761-781. Doi: $10.1177 / 0959354306070527$

Goldman, A. I. (2004). Epistemology and the evidential status of introspective reports. Journal of Consciousness Studies, 11, 1-16.

Gonçalves, O. (1994). Cognitive narrative psychotherapy: The hermeneutic construction of alternative meanings. Journal of Cognitive Psychotherapy, 8 , 105-126.

Greenberg, L. S. (2012). Emotions, the great captains of our lives: Their role in the process of change in psychotherapy. American Psychologist, 67, 697707. Doi: $10.1037 / \mathrm{a} 0029858$

Hofmann, S. G., Asnaani, A., Vonk, I. J. J., Sawyer, A. T. \& Fang, A. (2012). The efficacy of cognitive-behavioral therapy: A review of meta-analyses. Cognitive Therapy \& Research, 36, 427-440. Doi:10.1007/s10608-0129476-1.

Hollon, S., \& Beck, A. T. (1994). Cognitive and cognitive-behavioral therapies. In A.E. Bergin \& S.L. Gardfield (Eds.), Handbook of psychotherapy and behavior change (4th ed.) (pp. 428-466). New York, NY: Wiley.

Ibáñez, E. (1990, June). Presupuestos básicos y clasificación de las terapias cognitivas: Un punto de vista para la psiquiatría [Basic assumptions and classification of cognitive psychotherapies. A view for psychiatry] Paper addressed at the XVIII Congreso Nacional de la Sociedad Española de Psiquiatría, Salamanca, Spain

Ibáñez, E. (1993). Bosquejo para el análisis de las relaciones entre personalidad y psicoterapia [An outline for the relationships between personality and psychotherapy]. In I. Caro Gabalda (Ed.), Psicoterapia e investigación de procesos [Psychotherapy and processes research], (pp. 351-369). Valencia, Spain: Promolibro.

James, I. A., Southam, L. \& Blackburn, I. M. (2004). Schemas revisited. Clinical Psychology and Psychotherapy, 11, 369-377. Doi: 10.1002/cpp.423

James, W. (1884). On some omissions of introspective psychology. Mind, 33, 1-26.

James, W. (1890). Principles of psychology (Vol.1). New York, NY: Henry Holt \& Co.

Kelly, G. A. (1955). The psychology of personal constructs. New York, NY: W.W. Norton.

Korzybksi, A. (1933). Science and sanity. An introduction to non-aristotelian systems and general semantics. Brooklyn, NY: Institute of General Semantics.

Kvale, S. (1992). Postmodern psychology: A contradiction in terms? In S. Kvale (Ed.), Psychology and postmodernism (pp. 31-57). London, England: Sage.

Lambie, J.A. \& Marcel, A.J. (2002). Consciousness and the varieties of emotion experience: A theoretical framework. Psychological Review, 109, 219 259. Doi: $10.1037 / / 0033-295 X .109 .2 .219$

Lather, P. (1992). Postmodernism and the human sciences. In S. Kvale (Ed.), Psychology and postmodernism (pp. 88-109). London, England: Sage.

Lyddon, W. J. \& Jones, J. V. (2001) (Eds.). Empirically supported cognitive therapies. New York, NY: Springer.

Mahoney, M. J. (1980). Psychotherapy and the structure of personal revolutions. In M.J. Mahoney (Ed.), Psychotherapy process. Current issues and future directions (pp.157-180). New York, NY: Plenum Press.

Mahoney, M. J. (1991). Human change processes. New York, NY: Basic Books.

Mahoney, M. J. (1995). Continuing evolution of cognitive sciences and psychotherapies. In R. Neimeyer \& M. Mahoney (Eds.), Constructivism in psy chotherapy (pp. 39-68). Washington, DC: American Psychological Association.

Mahoney, M. \& Gabriel, T. (1987). Psychotherapy and the cognitive sciences: An evolving alliance. Journal of Cognitive Psychotherapy, 1, 39-59.

Marcel, A. J. (2003). Introspective report. Trust, self-knowledge and science. Journal of Consciousness Studies, 10, 167-186.

Martin, J. \& Sugarman, J. (2000). Between the modern and the postmodern. The possibility of self and progressive understanding in psychology. American Psychologist, 55, 397-406. Doi: 10.1037//0003-066X.55.4.397

Meichenbaum, D. O. (1977). Cognitive behavior modification: An integrative approach. New York, NY: Plenum Press.

Meichenbaum, D. O. (1995). Cognitive-behavioral therapy in historical perspective. In B. Bongar \& L. E Beutler (Eds.), Comprehensive textbook of psychotherapy (pp. 140-158). Oxford: Oxford University Press.

Minsky, M. (1985). The society of mind. New York: Simon \& Schuster.

Monsell, S. \& Driver, J. (2000). Banishing the control homunculus. In S. Monsell \& J. Driver (Eds.), Control of cognitive processes. Attention \& Performance XVIII (pp. 3-34). Berkshire: The International Association for the Study of Attention and Performance.

Moss, T. P. \& DiCaccavo, A. (2005). Understanding the schematic representation of pain and general symptomatology: The contribution of the cognitive miser perspective. Cognitive Therapy \& Research, 29, 511-524. Doi: 10.1007/s10608-005-3240-8

Neimeyer, R. A. (1993). An appraisal of constructivist psychotherapies. Journal of Consulting and Clinical Psychology, 61, 221-234. Doi: 10.1037/0022006X

Nisbett, R. E. \& Wilson, T. (1977). Telling more that we can know: Verbal reports on mental processes. Psychological Review, 84, 231-259. Doi: 10.1037/0033-295X.84.3.231

Operario, D. \& Fiske, S.T. (1999). Social cognition permeates social psychology: Motivated mental processes guide the study of human social behavior. Asian Journal of Social Psychology, 2, 63-78. Doi: 10.1111/1467839X.00026

Osatuke, K., Humphreys, C. L., Glick, M. J., Graff-Reed, R. L., McKenzie, L., \& Stiles, W. B. (2005). Vocal manifestations of internal multiplicity: 
Mary's voices. Psychology \& Psychotherapy, 78, 21-44. Doi: 10.1348/147608304X22364

Overgaard, M. (2006). Editorial. Introspection in science. Consciousness and Cognition, 15, 629-633. Doi: 10.1016/j.concog.2006.10.004

Padesky, C. (2004). Behavioural experiments: at the crossroads. In J. BennetLevy, G. Butler, M. Fennell, A. Hackman, M. Mueller \& D. Westbrook (Eds.). Oxford guide to behavioural experiments in cognitive therapy (pp. 433.438). Oxford, England: Oxford University Press.

Parkin, A. J. (1998). The central executive does not exist. Journal of the International Neuropsychological Society, 4, 518-522.

Pérez, M. (2004). Contingencia y drama [Contingency and drama]. Madrid, Spain: Minerva.

Pérez, M. (2012). Las raíces de la psicopatología moderna. La melancolía y la esquizofrenia. [The roots of modern psychopathology. Melancholy and schizophrenia] Madrid: Pirámide.

Persons, J. (1989). Cognitive therapy in practice. A case formulation approach. New York, NY: W.W. Norton.

Persons, J. (2008). The case formulation approach to cognitive-behavior therapy. New York, NY: Guilford

Pinillos, J. L. (1983). Las funciones de la conciencia [Functions of consciousness]. Madrid, Spain: Real Academia de Ciencias Morales y Políticas.

Radford, J. (1974). Reflections on introspection. American Psychologist, 4, 245 250. Doi: $10.1037 / \mathrm{h} 0036079$

Robinson, D. N. (2010). Consciousness. The first frontier. Theory \& Psychology, 20, 781-793. Doi: 10.1177/0959354310369944

Rodríguez, A. (1993). La imagen del ser humano en la psicología social [The image of human being in social psychology]. Psicothema, 5, 65-79.

Rosenau, P. (1992). Postmodernism and the social sciences. Princeton, NJ: Princeton University Press.

Rosenbaum, P. \& Valsiner, J. (2011). The un-making of a method: From rating scales to the study of psychological processes. Theory \& Psychology, 21, 47-65. Doi: 10.1177/0959354309352913
Rosfort, R. \& Stanghellini, G. (2009). The feeling of being a person. Philosophy, Psychiatry and Psychology, 16, 283-290. Doi: 10.1353/ppp.0.0244

Safran, J. D. \& Segal, Z. V. (1990). Interpersonal processes in cognitive therapy. New York, NY: Basic Books.

Saint-Exupéry, A. (1943). The little prince. New York, NY: Reynal \& Hitchcock.

Schirrmacher, F. (2014). Ego. Madrid, Spain: Ariel.

Seoane, J. (1982). Del procesamiento de información al conocimiento social [From information processing to social knowledge]. In I. Delclaux \& J. Seoane (Eds.), Psicología cognitiva y procesamiento de la información [Cognitive psychology and information processing] (pp. 85-92). Madrid, Spain: Pirámide.

Seoane, J. (1985). Conocimiento y representación social [Knowledge and social representation]. In J. Mayor (Ed.), Actividad humana y procesos cognitivos (Homenaje a J. L. Pinillos) [Human activity and cognitive processes. Tribute to J.L. Pinillos] (pp.383-398). Madrid, Spain: Alhambra.

Seoane, J. (2005). Hacia una biografía del self [Toward a biography of the self]. Boletin de Psicologia, 85, 41-87.

Tye, M. (2007). Philosophical problems of consciousness. In M. Verlmans \& S. Schneider (Eds.), The Blackwell companion to consciousness (pp. 23-35). Oxford, England: Blackwell Publishing.

Vega de, M. (1982). La metáfora del ordenador: implicaciones y límites [The computer metaphor: implications and limits]. In I. Delclaux \& J. Seoane (Eds.), Psicología cognitiva y procesamiento de la información [Cognitive psychology and information processing] (pp. 63-84). Madrid, Spain: Pirámide.

Woolfolk, R. L. \& Richardson, F. C. (1984). Behavior therapy and the ideology of modernity. American Psychologist, 39, 777-786. Doi: 10.1037/0003066X.39.7.777

Yurica, C. L. \& DiTomasso, R. A. (2005). Cognitive distortions. In A. Freeman, S.H. Felgoise, A. M. Nezu, C.M. Nezu \& M.A. Reinecke (Eds.), Encyclopedia of cognitive behavior therapy (pp. 117-122). New York, NY: Springer.

(Article received: 09-06-2014; revised: 03-08-2014; accepted: 15-10-2014) 